\title{
The Perception of Nursing Leaders towards Communication and Relationship Management Competencies while using Dig- ital Platforms during COVID-19 pandemic in Qatar
}

\author{
Laith F. Daradkeh", Ralph C. Villar', Abdulqadir J. Nashwan ${ }^{1}$ \\ 1 Department of Nursing, Hazm Mebaireek General Hospital (HMGH), Hamad Medical Corporation (HMC), \\ P.O. Box 3050, Doha, Qatar
}

\begin{abstract}
:
Purpose: To evaluate nursing leaders' perception towards communication and relationship management competencies while using digital platforms during the COVID-19 pandemic.

Background: Communication and relationship management competencies among nursing leaders will ensure healthcare models are successfully implemented. Nursing leaders can achieve effective leadership by mastering these competencies leading to an overall improvement in the quality of nursing care. However, digital platforms have been rapidly evolving in the healthcare ecosystem and have been significant during the battle with COVID-19. It is crucial to ensure that nursing leaders can use digital platforms to communicate and practice efficient management in their operations, especially during a crisis when their services are vital.

Design: Descriptive, comparative study.

Methods: The study was conducted between February to March 2021. A 5-item Linkert-type questionnaire was adopted from the American Organization for Nursing Executives (2005) and was sent to identified nursing leaders in Hamad Medical Corporation through the official email.

Results: Two hundred fifty nurse leaders were invited to participate, but only 116 responded positively, translating to a response rate of $46.4 \%$. The male participants represented a larger proportion of $64.10 \%$, while the female was $35.90 \%$. Regarding the questionnaire, the Cronbach alpha was $\alpha>$ 0.987 , indicating that all items revealed a sufficient level of internal consistency. The respondents had a minimum of 0 and a maximum of $52.6 \mathrm{n}$ in the communication and relationship management items. Influencing behavior, relationship management, and effective communication had the lowest scores, which indicate low competency. The F value in ANOVA analysis was close to 1.0, implying that the null hypothesis is true. The significance value is $<0.5$ implying that there is a difference in response on effective communication proficiency of nurse leaders.

Conclusions: Digital platforms are communication tools that are widely adopted to engage and reach nurses on numerous topics. Nurse leaders should capitalize on their benefits and generate critical discussions. The continued need to research nursing leadership competencies is critical as healthcare continues to change and evolve. Educational institutions and healthcare organizations must understand that nursing leaders should strive for professional development and knowledge acquisition to improve their communication and management.
\end{abstract}

Keywords: Nurses, leaders, COVID-19, management, communication

\section{Introduction}

Nowadays, nursing leaders must have advanced management talent to correspond to the continuously increasing demands and complexity in healthcare services provision [1]. Nursing Leaders are expected to show measurable outcomes and efficiency to facilitate effective practice with evidence-based management. Most academic studies and nursing leaders' programs emphasize on competencies management related to working 
environment effectiveness. The shift to evidence-based management has led to numerous efforts to define appropriate competencies for nursing leaders [2]. For example, communication and relationship management competency relates to how the leaders understand the individuals they work with and how they use their knowledge effectively in developing high-performance workplace relationships, in addition to how they utilize digital platforms to manage their working environment [3].

The American Organization of Nurse Executives (AONE), which is a member of the Healthcare Leadership Alliance (HLA), defined eight main domains correlated with this competency [3]. Most of these domains concentrate on communication and relationship management at the organizational level (e.g., understanding the corporation's structure and relationships, public relations, communicating the corporation's mission and vision). Other domains concentrate on the departmental level (e.g., promoting alternative conflict resolution, practicing and evaluating shared decision making, and building, engaging in, and leading teams) [4]. Mastering these competencies is only an entry ticket for leadership effectiveness, and the competency should be continuously utilized within the daily practice as part of continuous professional development. Over time, with continuous utilization, this competency can greatly improve the effectiveness of nursing leadership, and thus the quality of nursing care delivered to service users.

The HLA engaged in a formal process to delineate the knowledge, skills, and abilities within each domain and to determine which of these competencies were core or common among the membership of all HLA associations and which were specialty items specific to the members of one or more HLA organizations. This process produced 300 competency statements, which were then organized into the Competency Directory, a unique and interactive database that can assess individual and organizational competencies. Overall, this work helps to unify healthcare management and provides a taxonomy for collaboration among different types of healthcare executives [2].

A report from the IOM (2010), entitled The Future of Nursing: Leading Change, Advancing Health, recommended transformational changes in nursing education and practice, which position nurses to be a strong influence in shaping healthcare delivery systems, healthcare policy, and overall healthcare practices in the future. One specific recommendation is to prepare nurses at all levels to assume leadership positions. Several leadership competency models are in academia and practice and can be used for leadership development [5].

The COVID-19 pandemic has created an urgent need for coordinated mechanisms to respond to outbreaks across health sectors, and digital health solutions have been identified as promising approaches to meet this challenge [6-10]. To reduce the risk of infection; telemedicine has been used as a successful healthcare model in both emergency and primary care [11]. Official communication plans should promote easy and varied channels to inform people of the epidemic, avoid rumors and reduce threats to public health. Social media platforms such as Microsoft Teams ${ }^{\mathrm{TM}}$ and Google Trends are very useful for modeling trends in the epidemic and monitoring the evolution of patient symptoms or general reactions to and outcomes of an epidemic over time. 


\subsection{Problem statement}

It is crucial to ensure that nursing leaders are able to use digital platforms to communicate smoothly with their patients and practice efficient management in their operations, especially during crises situations, when their services are most vital.

\subsection{Significance}

Insight from this research will help nursing leaders to increase their resilience, agility, and learning on more effective ways to utilize technology during the pandemic. It may also challenge healthcare leaders to address safe quality care, workforce, and patient and family challenges.

\subsection{Study purpose}

The purpose of this study is to identify the perceived level of nursing leader's communication and relationship management competencies when using digital platforms. The objectives of the study are:

- To evaluate nursing leaders' perception towards communication and relationship management competencies while using digital platforms during the COVID-19 pandemic.

- To compare different professional levels (Executive Director of Nursing, Assistant Executive Director of Nursing, Director of Nursing, and Head Nurses of various units) communication and management competencies.

\subsection{Research questions}

- What is the level of perception towards communications and relationship management while using digital platforms during COVID-19 among nursing leaders in HMC?

- Is there a difference in the level of perception towards communications and relationship management while using digital platforms during COVID-19 among nursing leaders in HMC?

\section{Materials and Methods}

This study was conducted in different hospitals under Hamad Medical Corporation (HMC) in Qatar, the largest healthcare provider in the country.

\subsection{Design}

A descriptive comparative study design was used to answer the research questions during the period from February to March 2021.

\subsection{Population and Sample}

The target population was the nursing leaders across HMC (Executive Director of Nursing, Assistant Executive Director of Nursing, Director of Nursing, and Head Nurses of various units).

\subsection{Data Collection and Settings}

An official email was sent from the researcher through the HMC research department to all targeted participants, explaining the nature and scope of the study and the voluntary nature of participation, including the right to withdraw at any time and the right to anonymity. Completion of the questionnaire was considered as approval of participation. Participants were informed that they had 2 weeks to fill in the questionnaire. Reminders were sent by email to complete the survey to improve the response rate. 
The study was conducted across HMC, which is the largest healthcare provider in Qatar. HMC currently manages 12 hospitals, nine specialist hospitals, and three community hospitals. Over 12,000 nurses are working under HMC.

\subsection{Instruments}

A 5-item Linkert-type questionnaire about communication and relationship management competencies was adopted from the American Organization of Nurse Executives questionnaire (AONE, 2005).

\subsection{Ethical approval}

The study was conducted in full conformance with principles of the "Declaration of Helsinki", Good Clinical Practice (GCP), and within the laws and regulations of MoPH in Qatar. Implied consent was obtained from the participants, and the researcher assured voluntary participation for the subjects. Also, the questionnaire was disseminated without names or corporation numbers to assure participant anonymity and data confidentiality. Original authors provided the researcher with permission to use the scales. The researcher adhered to the ethical codes and regulations of the University of Essex and got permission from the IRB of HMC (MRC-01-21-090).

\subsection{Statistical Analysis}

The Statistical Package for the Social Sciences (SPSS) IBM, version 25 was used to analyze the data. Descriptive statistics, including percentages, frequencies, means, and standard deviations, were used to describe the sample and answer the research questions about the perception of communication and relationship management competencies. Cronbach's alpha. In addition, ANOVA and Wilcoxon-rank sum tests were done to compare the status of communications and relationship management competencies.

Assumptions were checked and insured before using the Inferential statistics. The researcher checked the outliers and the missing values and dealt with them appropriately. Then, the researcher ran the analysis. The data were considered significant when P-value $<0.05$.

\section{Results}

From 250 eligible participants, 116 responded positively took the invitation translating to a $46.4 \%$ response rate.

\subsection{Sample characteristics}

The majority of participants are male, consisting $63.8 \%$ of the sample size, while women were $36.2 \%$. Nursing leaders were represented in all departments where $60.4 \%$ were Head Nurses, $28.4 \%$ were Directors of Nursing, and 11.2\% were Executive Directors and Assistant Executive Directors of Nursing. Years of experience ranged from to above ten years. The majority of the participants have above 10 years of experience (53.5\%). 
Table 1. Participants' socio-demographics and work-related factors $(n=116)$

\begin{tabular}{|c|c|c|c|}
\hline & Variables & Frequency & Percentage \\
\hline \multirow{2}{*}{ Gender } & Male & 74 & 63.8 \\
\hline & Female & 42 & 36.2 \\
\hline \multirow{4}{*}{$\begin{array}{l}\text { Current Posi- } \\
\text { tion in HMC }\end{array}$} & Executive Director of Nursing & & \\
\hline & $\begin{array}{l}\text { Assistant Executive Director of } \\
\text { Nursing }\end{array}$ & 13 & 11.2 \\
\hline & Director of Nursing & 33 & 28.4 \\
\hline & Head Nurse & 70 & 60.4 \\
\hline \multirow{3}{*}{$\begin{array}{l}\text { Experience in } \\
\text { current posi- } \\
\text { tion }\end{array}$} & $0-5$ years & 23 & 19.8 \\
\hline & $5-10$ years & 31 & 26.7 \\
\hline & Above 10 years & 62 & 53.5 \\
\hline
\end{tabular}

\subsection{Reliability}

The results of the study showed that all the items revealed a sufficient level of internal consistency with Cronbach alpha $(\alpha>0.987)$.

Table 2. Reliability Test

\begin{tabular}{|c|c|c|}
\hline Cronbach's Alpha & $\begin{array}{l}\text { Cronbach's Alpha } \\
\text { Based on Standardized Items }\end{array}$ & $\mathrm{N}$ of Items \\
\hline .986 & .987 & 7 \\
\hline
\end{tabular}

\begin{tabular}{|c|c|c|c|c|c|}
\hline & $\begin{array}{l}\text { Scale Mean if Item } \\
\text { Deleted }\end{array}$ & $\begin{array}{l}\text { Scale Variance if Item } \\
\text { Deleted }\end{array}$ & $\begin{array}{l}\text { Corrected Item-Total } \\
\text { Correlation }\end{array}$ & $\begin{array}{l}\text { Squared Multiple } \\
\text { Correlation }\end{array}$ & $\begin{array}{l}\text { Cronbach's Alpha if } \\
\text { Item Deleted }\end{array}$ \\
\hline Effective communication & 122.560 & 13301.348 & .996 & . & .981 \\
\hline Relationship management & 122.940 & 13529.473 & .993 & . & .981 \\
\hline Influencing behaviors & 122.760 & 13529.068 & .997 & . & .981 \\
\hline Shared decision making & 123.720 & 13465.312 & .850 & . & .991 \\
\hline Community involvement & 123.640 & 13770.793 & .865 & . & .989 \\
\hline Medical staff relationship & 123.340 & 13217.923 & .975 & . & .982 \\
\hline Academic relationship & 123.240 & 13568.908 & .982 & . & .982 \\
\hline
\end{tabular}

\subsection{Descriptive}

The descriptive statistics for each communication and relationship management competency indicate the mean, minimum, maximum, and standard deviation. The distribution of the competency rating allows researchers to identify areas where there are larger variations. In turn, it can help healthcare organizations identify specific competencies that require further development. This research provides answers to the 
research question as the required communications and relationship management competencies were evaluated. The implications of the results have been provided in the conclusion section.

A participant can score a maximum of 52.6 and a minimum of 0 from the communications and relationship management items. From the items of digital competency, Effective communication, relationship management, and influencing behavior were rated the lowest, with 44.0, 42.0, and 43.0, indicating they have a low level of competency

Table 3. Nursing Leaders' Communication and Relationship Management Competency Scores

\begin{tabular}{|c|c|c|c|c|c|}
\hline & $\mathrm{N}$ & Minimum & Maximum & Mean & Std. Deviation \\
\hline \multirow[t]{2}{*}{ Effective communication } & 5 & .0 & 44.0 & 21.140 & 20.0 \\
\hline & & & & & 486 \\
\hline \multirow[t]{2}{*}{ Relationship management } & 5 & 3.0 & 42.0 & 20.760 & 19.1 \\
\hline & & & & & 230 \\
\hline \multirow[t]{2}{*}{ Influencing Behaviors } & 5 & 3.0 & 43.0 & 20.940 & 19.0 \\
\hline & & & & & 491 \\
\hline \multirow[t]{2}{*}{ Shared decision making } & 5 & .0 & 52.6 & 19.980 & 22.0 \\
\hline & & & & & 819 \\
\hline \multirow[t]{2}{*}{ Community involvement } & 5 & 2.0 & 52.0 & 20.060 & 20.3 \\
\hline & & & & & 264 \\
\hline \multirow[t]{2}{*}{ Medical staff relationship } & 5 & .8 & 49.8 & 20.360 & 20.7 \\
\hline & & & & & 963 \\
\hline \multirow[t]{2}{*}{ Academic relationship } & 5 & 1.5 & 44.5 & 20.460 & 19.1 \\
\hline & & & & & 346 \\
\hline Valid N (listwise) & 5 & & & & \\
\hline
\end{tabular}

3.4. Differences in Nurses' Leaders Perception of Communication and Relationship Management Competency

Hernandez et al. (2018) define leadership as the ability of individuals to inspire organizational and individual competence, successfully manage change, and create a shared vision to achieve a successful performance and organization's strategies [12]. The participants rated the overall communications and relationship management competencies and proficiency level related to digital platform utilization by nurse leaders.

The items have an $\mathrm{f}$ value close to 1.0, indicating that the null hypothesis is true. The significance indicates that even though there is a difference in response on effective communication proficiency of nurse leaders, the difference is statistically significant because it is less than 0.5 . That implies that it would occur $41.1 \%$ in influencing behavior, $40.9 \%$ in relationship management, $40.4 \%$ in shared decision making, 40.1 
in community involvement, $23.4 \%$ in medical staff relationship, and $40.3 \%$ in an academic relationship.

Table 4. Differences in Nurses' Leaders Perception of Communication and Relationship Management Competency

\begin{tabular}{|c|c|c|c|c|c|c|}
\hline & & Sum of Squares & $\mathrm{df}$ & Mean Square & F & Sig. \\
\hline \multirow{4}{*}{$\begin{array}{l}\text { Influencing } \\
\text { behaviors }\end{array}$} & Between Groups & 1451.472 & 4 & 362.868 & 0.677 & 0 \\
\hline & & & & & & .411 \\
\hline & Within Groups & .000 & 0 & . & & \\
\hline & Total & 1451.472 & 4 & & & \\
\hline \multirow{4}{*}{$\begin{array}{l}\text { Relationship } \\
\text { management }\end{array}$} & Between Groups & 1462.752 & 4 & 365.688 & 0.681 & 0 \\
\hline & & & & & & .409 \\
\hline & Within Groups & .000 & 0 & . & & \\
\hline & Total & 1462.752 & 4 & & & \\
\hline \multirow{4}{*}{$\begin{array}{l}\text { Shared deci- } \\
\text { sion making }\end{array}$} & Between Groups & 1950.448 & 4 & 487.612 & 0.887 & 0 \\
\hline & & & & & & .404 \\
\hline & Within Groups & .000 & 0 & . & & \\
\hline & Total & 1950.448 & 4 & & & \\
\hline \multirow{4}{*}{$\begin{array}{l}\text { Community } \\
\text { involvement }\end{array}$} & Between Groups & 1652.652 & 4 & 413.163 & 0.729 & 0 \\
\hline & & & & & & .401 \\
\hline & Within Groups & .000 & 0 & . & & \\
\hline & Total & 1652.652 & 4 & & & \\
\hline \multirow{4}{*}{$\begin{array}{l}\text { Medical staff } \\
\text { relationship }\end{array}$} & Between Groups & 1729.952 & 4 & 432.488 & 0.912 & 0 \\
\hline & & & & & & .234 \\
\hline & Within Groups & .000 & 0 & & & \\
\hline & Total & 1729.952 & 4 & & & \\
\hline \multirow{4}{*}{$\begin{array}{l}\text { Academic re- } \\
\text { lationship }\end{array}$} & Between Groups & 1464.532 & 4 & 366.133 & 0.793 & 0 \\
\hline & & & & & & 403 \\
\hline & Within Groups & .000 & 0 & . & & \\
\hline & Total & 1464.532 & 4 & & & \\
\hline
\end{tabular}

\section{Discussion}

This result offers practical insight for evaluating expertise in crucial areas of communication and relationship management competencies. Lucas et al. (2018) argue that the competency assessment tools may be utilized in various ways to detect strengths and improvement areas [13]. This result can be utilized in enhancing the following areas: (a) Group or team development as the tool can help link individual goals of a team to the organizational objectives, resulting in corporate values, goals, and objectives. (b) Organisational and self-assessment provide valuable information of strengths and weaknesses in communication and relationship management competencies to inform a professional improvement strategy. (c) Professional and 
academic development programs can help uncover skills, knowledge, and specific competencies that programs should focus on when offering professional development programs.

The study categorized all nursing leaders into a single sample and evaluated the direct correlation between communication and relationship management competency and leadership proficiency. This research aligns with previous studies that argue that healthcare leaders at the competent and intermediate levels have the highest rate of competency. Hernandez et al. (2018) assert that the nursing leader understands the importance of prioritizing and linking it to the set goals; however, the leader lacks proficiency speeds. Most digital platforms for healthcare providers allow them to contribute in online groups, listen to other experts, and communicate or network with their colleagues concerning patient issues [12].

In the proficiency level subscale, participants scored the highest mean in effective communication, and the lowest mean in shared decision making. Influencing behavior scored the lowest standard deviation, and shared decision-making had the highest standard deviation indicating minimal dispersion in the data. The digital platforms that enhance professional networking are only available and cater to individuals within these nursing professions [14]. In addition, discussions and clinical topics in such sites often address diverse subjects, including biostatistics, ethics, practice management, politics, and career strategies [15]. The results from this study indicate that digital platforms provide a supportive environment for nursing leaders. Digital platforms also enhance crowdsourcing that involves harnessing skills and knowledge of the society to gather opinions and information or solve problems [16]. According to Hernandez et al. (2018), social media connects nurse leaders in developing countries with those from more medically advanced nations. Digital platforms connect a broader nursing audience and magnify content and key themes [12]. From the responses in the survey, nurse leaders who use digital platforms, the assistance and information received were helpful. Shared decision making and community involvement had the highest maximum values of 52.6 and 52.0 in the descriptive table.

According to Lucas et al. (2018), nurse leaders can ask questions on Twitter or stream surgical procedures through the internet [13]. Therefore, digital platforms offer a new communication channel for nurse leaders to network, exchange, and share medical information in ways and at a pace that was never possible before.

The improvement in communication provided by digital platforms plays a critical role in improving clinical education. Hernandez et al. (2018) argue that the high utilization rate of digital platforms by individuals between 18 years and 29 years fostered the adaptation of clinical curricula to reflect incoming students' culture the changing habits [12]. This study's results indicate that the F-value of the academic relationship is 0.793 indicating the null hypothesis is true. That implies that nurse leaders actively use digital platforms to improve students' understanding of ethics, communication, and professionalism.

The focus of the benefits of digital platforms in enhancing nursing leaders' work within the society came across strongly because of the need to provide integrated social and healthcare services in Qatar and the international emphasis to improve primary care to 
support patient self-management at home [17]. The nursing workforce needs to have a high level of generalized information and coordination, excellent communication, and leadership skills, which will ensure they can navigate the complex online environment and effectively deliver healthcare services to the community. Furthermore, the advanced practice roles catering to the needs of patients will be critical for the aging population as it is now a global trend [13]. Therefore, there is a need to research the specialized healthcare services that the patients require, how to develop and implement them in nursing practice, education, the level of demand, and policies governing the integration agenda, ensuring nurses are adequately equipped for the future.

COVID-19 has increased the need to deliver care remotely through networked care delivery and mobile consultations to limit the need for direct contact. Mast et al. (2018) argue that since healthcare providers will not physically examine the patients, clear guidance and good support to the patient is critical to ensure effective treatment and diagnosis at a distance [18]. The findings of the study show that digital platforms allow nurses to provide ongoing guidance and support. The digital platform creates a need for nursing leaders to provide knowledge to patients to ensure they can evaluate and interpret the information from monitoring mechanisms to empower their decisionmaking process.

Nursing leaders should ensure transparent and clear communication between the user and the professional. The clarity, listening skills, and voice intonation of virtual communication information are essential as face-to-face support and prompts are absent. For example, healthcare professionals may communicate through video or audio connections provided on digital platforms [19]. This study's findings indicate that specific competencies needed for remote healthcare service provision include providing consultations to the community, being an effective member of professional organizations, representing organizations of non-health within the community.

Chen (2018) argues that nurse leaders may be required to engage other healthcare providers when making healthcare-related decisions and should ensure that the patients' health information is shared responsibly [15]. The study highlights confidentiality concerns and argues that digital platforms should enhance the responsible sharing of information across and between organizations. But, nursing leaders should ensure regular communication to enhance teamwork with other healthcare shareholders such as healthcare organizations, communities, caregivers, nurses, physicians, and voluntary groups. In addition, nursing leaders must be aware of the implications of digital platforms across a broader integrated spectrum of healthcare services.

Krawczyk-Sołtys (2017) argues that there is a risk of breaching patients' confidentiality and privacy when nurses share patient information during interactions on digital platforms [14]. The study results suggest that nurse leaders should be aware of the specific ways that digital platforms compromise patients' confidentiality and privacy and how patients' right to know how the information is viewed and shared. Although most healthcare organizations have standards for data sharing, digital platforms alter how healthcare providers view and share information. It results in unique patient data requirements and how these data can be kept secure from others using online tools and 
mobile devices [16]. Since digital platforms draw nursing leaders from various organizations, they must monitor information access [17]. They need to enhance effective information sharing across nurse leaders while considering legislation rules and national privacy laws.

\subsection{Strengths and limitations}

This research was generated within a short period; therefore, it might affect the generalization. In addition, the study had a small sample population, as well as the time of introducing the survey may lead to information bias. The sample size consisted of 116 participants, which represented a $34.48 \%$ response rate. Similar research should be carried out with a larger sample size to ascertain the results.

\subsection{Conclusions}

Digital platforms are communication tools that are widely adopted to engage and reach nurses on numerous topics. Nurse leaders should capitalize on their benefits and generate critical discussions. They can also implement horizon scanning to detect future nursing priorities. The continued need to research nursing leadership competencies is critical as healthcare continues to change and evolve. Educational institutions and healthcare organizations must understand that nursing leaders should strive for professional development and knowledge acquisition to improve their communications and relationship management competencies. People should know the competency proficiency level that healthcare leaders should attain. This study can be used to evaluate the competency proficiency level of graduate healthcare leadership students. The knowledge can help healthcare organizations to identify the training needs of employees.

\subsection{Recommendations}

Increased use of digital platforms in the healthcare setting creates a need for experts to research them to identify the bottlenecks associated with them and discover ways to implement digital platforms in healthcare settings successfully. Nursing leaders gain from including digital platforms in their engagement strategies, particularly during the COVID-19 pandemic, and should consider the following when using digital platforms to enhance healthcare service provision. First, they should consider the social media policies issued by a professional association or within the healthcare organization.

It may be useful to adopt an engagement approach. For instance, the National Council of State Boards of Nursing offers useful guidance on ways nurses should use social media to minimize risks and maximize online interaction benefits. Improved expertise in tracking analytics and participating in social media campaigns may be critical to support delivery, evaluation of communication, and design because it requires specialist support. Detailed plans to enhance social media engagement activity such as deciding on the audience, objective or ultimate goal, how best to reach them, and the digital media platform to use. In addition, Nursing leaders should be keen when determining the appropriate branding or hashtag for the subject matter, agreeing on how to conduct the online discussion, selecting the metrics and analytics to use, ways of evaluating the results of the online discussions, and how they will be transmitted to the relevant shareholders should be done accurately by nursing leaders. These steps 
will ensure nursing leaders effectively implement their social media strategy and attain higher participation of nurses who will inform health policy.

One benefit of digital platforms is that they are open such that in case a person misses the conversation, they can quickly access the discussion that occurred, therefore, guaranteeing transparency. Unfortunately, this also poses a major problem as unsavory content can be posted to the discussion since most digital platforms are not moderated. That implies that there are elements of organizational risk in utilizing digital platforms professionally. It also raises the need to improve staff capacity in various ways, such as providing focused and continuous training for healthcare providers. Some nursing associations have established guidelines that advise their employees on successfully navigating the digital platforms. However, further research is required on the professional and ethical issues linked to digital platforms in nursing research, education, and training which would help protect students, nurses, lecturers, and patients and certify that they are competent to explore the online environments. Nurse leaders should also assess how analytics in digital platforms are driven and designed. There are some standard metrics, but the use and definition of platforms vary; therefore, they can be misleading. For instance, in Twitter, the term impressions are employed to refer to tweets posted to a tweeter stream. The impressions exclude social media information that is streamed to third-party applications such as Hootsuite. Therefore, the analytics reflect the size of the potential audience. Replies and retweets are other engagement metrics, which are more precise. However, bots, the automated algorithms or software, pose as real users in digital platforms, may be problematic. They may significantly increase the engagement metrics in misinformation by retweeting, liking posts, and following users. That implies a need for more nursing research that will help understand the disadvantages and advantages of Digital platform analytics, which will help educate nurse leaders and ensure nurses understand the drawbacks and benefits in interpreting virtual behaviors and online environments.

\section{Author contributions}

Funding: This study was funded by the Medical Research Center at Hamad Medical Corporation (MRC-01-21-090).

Institutional Review Board Statement: The study was approved by the Medical Research Center (MRC) - Institutional Review Board (IRB) at Hamad Medical Corporation (MRC-01-21-090).

Informed Consent Statement: Implied consent was obtained from the participants, and the researcher assured voluntary participation for the subjects. Also, the questionnaire was disseminated without names or corporation numbers to assure participant anonymity and data confidentiality.

Data Availability Statement: All data generated during this study are included in this published article.

Conflicts of Interest: The authors declare that they have no competing interests.

Acknowledgments: This study was funded by the Medical Research Center at Hamad Medical Corporation (MRC-01-21-090). 


\section{References}

1. Cheryl Lacasse, M. Developing nursing leaders for the future: Achieving competency for transformational leadership. In Proceedings of the Oncology Nursing Forum, 2013; p. 431.

2. Stefl, M.E. Common competencies for all healthcare managers: the healthcare leadership alliance model. Journal of healthcare management 2008, 53.

3. Garman, A.N.; Johnson, M.P. Leadership competencies: An introduction. Journal of Healthcare Management 2006, 51, 13 .

4. Reid Ponte, P. The American health care system at a crossroads: An overview of the American Organization of Nurse Executives monograph. Online Journal of Issues in Nursing 2004, 9, 1-11.

5. Fitzpatrick, J.J. The future of nursing: Leading change, advancing health. Nursing Education Perspectives 2010, 31, 347-348.

6. Nashwan, A.J.; Abujaber, A.A.; Villar, R.C.; Nazarene, A.; Al-Jabry, M.M.; Fradelos, E.C. Comparing the Impact of COVID-19 on Nurses' Turnover Intentions before and during the Pandemic in Qatar. Journal of Personalized Medicine 2021, 11, 456.

7. Allobaney, N.F.; Nashwan, A.J.; Mohamed, A.S. Nursing Research during COVID-19 Pandemic: A Scoping Review. Open Journal of Nursing 2020, 10, 952-959.

8. Nashwan, A.J.; Abujaber, A.A.; Mohamed, A.S.; Villar, R.C.; Al-Jabry, M.M. Nurses' willingness to work with COVID-19 patients: The role of knowledge and attitude. Nursing Open 2021, 8, 695-701.

9. Nashwan, A.J.; Villar, R.C.; Al-Qudimat, A.R.; Kader, N.; Alabdulla, M.; Abujaber, A.A.; Al-Jabry, M.M.; Harkous, M.; Philip, A.; Ali, R. Quality of life, sleep quality, depression, anxiety, stress, eating habits, and social bounds in nurses during the coronavirus disease 2019 pandemic in qatar (The PROTECTOR study): A cross-sectional, comparative study. Journal of Personalized Medicine 2021, 11, 918.

10. Villar, R.C.; Nashwan, A.J.; Mathew, R.G.; Mohamed, A.S.; Munirathinam, S.; Abujaber, A.A.; Al-Jabry, M.M.; Shraim, M. The lived experiences of frontline nurses during the coronavirus disease 2019 (COVID-19) pandemic in Qatar: A qualitative study. Nursing Open 2021.

11. Fagherazzi, G.; Goetzinger, C.; Rashid, M.A.; Aguayo, G.A.; Huiart, L. Digital health strategies to fight COVID-19 worldwide: challenges, recommendations, and a call for papers. Journal of Medical Internet Research 2020, 22, e19284.

12. Hernandez, S.R.; O'connor, S.J.; Meese, K.A. Global efforts to professionalize the healthcare management workforce: the role of competencies. The Journal of health administration education 2018, 35, 157.

13. Lucas, R.; Goldman, E.F.; Scott, A.R.; Dandar, V. Leadership development programs at academic health centers: results of a national survey. Academic Medicine 2018, 93, 229-236.

14. Krawczyk-Sołtys, A. From healthcare manager's competencies to healthcare organization's competences. Vadyba 2017, 31, 9-15.

15. Chen, T.-Y. Medical leadership: An important and required competency for medical students. Tzu-chi medical journal 2018, 30, 66.

16. Shum, C.; Gatling, A.; Shoemaker, S. A model of hospitality leadership competency for frontline and directorlevel managers: Which competencies matter more? International Journal of Hospitality Management 2018, 74, 5766.

17. Handtke, O.; Schilgen, B.; Mösko, M. Culturally competent healthcare-A scoping review of strategies implemented in healthcare organizations and a model of culturally competent healthcare provision. PloS one 2019, 14, e0219971. 
18. Mast, L.J.; Winter, B.; Ross, M.; McIntyre-Hite, L. Program Management for Faculty Development: Addressing the Changing Faculty Roles in a Direct Assessment Competency-Based Model. The Journal of Health Administration Education 2018, 35, 279.

19. Collins, S.; Yen, P.-Y.; Phillips, A.; Kennedy, M.K. Nursing informatics competency assessment for the nurse leader: The Delphi study. JONA: The Journal of Nursing Administration 2017, 47, 212-218. 